Revista de Derecho YACHAQ

ISSN: 1817-597x (impresa) / ISSN: 2707-1197 (en linea)

Centro de Investigación de los Estudiantes de Derecho (CIED)

Universidad Nacional de San Antonio Abad del Cusco

N. ${ }^{\circ} 10-2019$

[pp. 141-152]

Fecha de recepción: 11/08/19

Fecha de aceptación: 18/09/19

\title{
Reflexión y análisis del delito de concusión en el código penal peruano
}

\section{Reflection and Analysis of the Crime of Concussion in the Peruvian Penal Code}

\author{
Marie Melisa Gonzales Cieza[*] \\ David Ricardo Torres Pachas ${ }^{[* *]}$
}

\begin{abstract}
RESUMEN: en el presente artículo los autores se encargan de desarrollar los elementos del delito de concusión en el Código Penal peruano. Se explica el origen histórico, los principales aspectos problemáticos en relación con los elementos objetivos, subjetivos, así como la situación de la víctima en el referido delito.
\end{abstract}

ABSTRACT: in this article the authors develop the elements of the crime of concussion in the Peruvian Penal Code. They explain the historical origin, the problematic aspects in relation to the objective and subjective elements and the situation of the victim in the mentioned crime.

PALABRAS CLAVES: concusión, corrupción, administración pública.

KEY WORDS: concussion, corruption, public administration.

[*] Estudiante en la Facultad de Derecho de la Pontificia Universidad Católica del Perú (PUCP). Practicante preprofesional del Equipo Anticorrupción del Instituto de Democracia y Derechos Humanos de la PUCP (IDEHPUCP) y miembro del Grupo de Investigación en Derecho Penal y Corrupción (DEPEC) de la PUCP. Asistente de docencia del curso Instituciones del Derecho Sancionador en la PUCP. Exdirectora de la comisión de Investigación Académica y miembro extraordinario de la Asociación IUS ET VERITAS. Contacto: m.gonzalesc@pucp.pe.

[**] Abogado por la Pontificia Universidad Católica del Perú (PUCP). Estudiante del Máster en Estrategias Anticorrupción y Políticas de Integridad en la Universidad de Salamanca (España) y miembro del Grupo de Investigación en Derecho Penal y Corrupción (DEPEC) de la PUCP. Ha sido investigador del Equipo Anticorrupción del Instituto de Democracia y Derechos Humanos de la PUCP (IDEHPUCP) y adjunto de docencia de los cursos Instituciones del Derecho Sancionador, Teoría del Delito, Temas de Derecho Penal, Delitos contra la Administración Pública y Clínica Jurídica - Sección Estado de Derecho y Lucha contra la Corrupción y el Lavado de Activos en la PUCP. Expresidente de la Asociación Civil Iter Criminis (PUCP). Contacto: dtorrespachas@gmail.com. 


\section{INTRODUCCIÓN}

El delito de concusión aparece en Roma bajo la designación de crimen repetundarum, término que se utilizaba para designar la concusión, el cohecho y la negociación incompatible (Ramos, 1963, p. 14). Luego, con la aparición de la Ley Julia ${ }^{[1]}$, la concusión tuvo su propia legislación; sin embargo, no se logra establecer una distinción entre concusión y cohecho o corrupción (Ramos, 1963, p. 15).

Hay quienes mencionan que la Ley Julia sancionaba al funcionario obligándolo a devolver el valor duplicado de lo recibido mediante la extorsión (Reátegui, 2014, p. 143). Otros señalan que la Ley de las XII Tablas sancionaba incluso con la pena de muerte los casos de concusión del juez (Rojas, 2007, p. 350).

Durante el Imperio la concusión hacía referencia al acto por el cual un funcionario subalterno, simulando órdenes superiores o fingiendo atribuciones de cargos superiores, infundía temor en los ciudadanos con el fin de obtener alguna utilidad (Ferrini citado por Ramos, 1963, p. 15).

En el Perú, no existen antecedentes de este delito en el Código Penal de 1924 (Reátegui, 2014, p. 142). Su tipificación aparece con el Código Penal peruano de 1991 en el artículo 382, que fue modificado por la Ley N. ${ }^{\circ} 30111$ en el 2013 y luego por el Decreto Legislativo N. 1243 en el 2016. La norma extranjera que se empleó como modelo es el artículo 317 del Código Penal italiano de 1930 $0^{[2]}$, reformado por la Ley 86 en 1990 según el cual «El oficial público o el encargado de un servicio públi$\mathrm{co}$, que abusando de su cualidad o de sus poderes, constriñe $o$ induce a alguien a dar $o$ a prometer indebidamente, a él o a un tercero, dinero u otra utilidad, será castigado con reclusión de cuatro a doce años» (Reátegui, 2014, p. 578). Actualmente, el de- lito de concusión sanciona al funcionario o servidor público que, abusando de su cargo, obliga o induce a otra persona a entregarle o prometerle indebidamente un bien o beneficio patrimonial.

Si bien podría parecer un delito recurrente en nuestro país, de acuerdo con la Procuraduría Pública especializada en delitos de corrupción (2018), el delito de concusión representó tan solo el $4 \%$ de los delitos con mayor grado de incidencia a nivel nacional en el año 2018 (p. 13). Asimismo, sorprende la poca información que puede encontrarse en torno a este delito, el cual ha sido muy poco desarrollado por la doctrina peruana. Del mismo modo, son pocos los casos que se pueden encontrar en la jurisprudencia.

Sin embargo, es importante conocer todo lo que abarca este delito. Por ello, se reflexionará y analizará cada uno de los elementos del delito de concusión.

\section{SUJETOS DEL DELITO DE CONCUSIÓN}

En primer lugar, abordaremos el tema de los sujetos activo y pasivo en el delito de concusión.

\subsection{Sujeto activo}

El sujeto activo de este delito es el funcionario o servidor público que, abusando de su cargo, obliga o induce a otra persona a dar o prometer indebidamente un beneficio patrimonial[ ${ }^{[3]}$.

Es necesario que quien cometa este delito tenga la calidad de funcionario público. De acuerdo con la Convención Interamericana Contra la Corrupción ${ }^{[4]}$, tal condición engloba a «cualquier funcionario o empleado del Estado o de sus entidades, incluidos los que han sido seleccionados, designados o electos para desempeñar actividades

[1] Formó parte de las Doce Tablas.

[2] Redacción original: «El oficial público, que abusando de su cualidad o de sus poderes constriñe o induce a alguien a dar o a prometer indebidamente a él o a un tercero dinero u otra utilidad, será castigado con reclusión de cuatro a doce años y con multa no inferior a tres mil liras» (REATEGUI, 2014, p. 578).

[3] Artículo 382 del Código Penal peruano.

[4] Ratificada por el Perú mediante Decreto Supremo N. ${ }^{\circ}$ 012-97-RE. 
o funciones en nombre del Estado o al servicio del Estado, en todos sus niveles jerárquicos».

Del mismo modo, debe tomarse en cuenta lo mencionado en el artículo 425 del Código Penal:

\section{Artículo 425}

Son funcionarios o servidores públicos:

1. Los que están comprendidos en la carrera administrativa.

2. Los que desempeñan cargos políticos o de confianza, incluso si emanan de elección popular.

3. Todo aquel que, independientemente del régimen laboral en que se encuentre, mantiene vínculo laboral o contractual de cualquier naturaleza con entidades u organismos del Estado, incluidas las empresas del Estado o sociedades de economía mixta comprendidas en la actividad empresarial del Estado, y que en virtud de ello ejerce funciones en dichas entidades u organismos.

4. Los administradores y depositarios de caudales embargados o depositados por autoridad competente, aunque pertenezcan a particulares.

5. Los miembros de las Fuerzas Armadas y Policía Nacional.

6. Los designados, elegidos o proclamados, por autoridad competente, para desempeñar actividades o funciones en nombre $\mathrm{o}$ al servicio del Estado o sus entidades.

7. Los demás indicados por la Constitución Política y la ley.

Siendo ello así, un funcionario público puede definirse como «la persona natural seleccionada, designada o elegida para desempeñar función pública, esto es, para vincular y representar al Estado con sus actos» (Meini, 2012, p.5). Es importante mencionar que tal calidad de funcionario no es formal, sino que es funcional, pues el delito debe cometerse en el ejercicio de actos inherentes a su competencia ${ }^{[5]}$. En este punto, se debe analizar el abuso del cargo, el cual se configura cuando el servidor no respeta los límites y las normas que regulan sus facultades (Abanto, 2003, p. 288). Como lo menciona Mazini, solo puede abusar de una cosa aquel que tiene el derecho legítimo de usarla; por lo que no habrá concusión cuando quien cometa el hecho, pese a tratarse de un funcionario, usurpe funciones que no le corresponden (Citado por Reátegui, 2014, p. 146).

\subsection{Sujeto pasivo}

El sujeto pasivo de este delito es el Estado peruano, debido a que el funcionario no está actuando conforme a los deberes encomendados. La persona que entrega o promete un beneficio es víctima de la conducta del funcionario, ya que la obliga o induce a realizar actos contrarios a su voluntad.

Es importante tener en cuenta la diferencia que existe entre víctima y sujeto pasivo. El primero es el agraviado directo sobre quien recae la conducta del sujeto activo. El segundo es aquel que ha visto lesionado uno de sus bienes jurídicos a causa del delito cometido por el agente (Regalado, 2017, p. 8).

Como menciona Neuman, normalmente existe identidad entre el sujeto pasivo (titular del bien jurídico) y la víctima, pero habrá casos, como este, en los que no se trate del mismo individuo (Citado por Regalado, 2017, p. 8). Al tratarse de un delito contra la administración pública el Estado será el sujeto pasivo.

\section{BIEN JURÍDICO TUTELADO}

Como en todo delito de corrupción, el bien jurídico protegido (de manera genérica) es el correcto y regular funcionamiento de la administración pública (Salinas, 2011, p. 242). La cual deja de funcionar adecuadamente a causa de los actos corruptos cometidos por los funcionarios o servidores públicos. Es a partir de dicho bien jurídico genérico que luego debe identificarse cuál es el ámbito específico de la administración pública que se afecta o pone en peligro (Abanto, 2003, p.18).

[5] Como lo señala la R.N. N. ${ }^{\circ}$ 1601-2006 del 28 de enero de 2009. Así, también, el Exp. N. ${ }^{\circ}$ 44-06 del 7 de junio de 2011. 
En este sentido, la tipificación de este delito busca proteger, específicamente, el ejercicio de la función pública conforme a las normas que la regulan en su relación con los administrados. Así, pues, por ejemplo, el artículo 7, inciso 4 del Código de Ética de la Función Pública, menciona el principio de ejercicio adecuado del cargo, en virtud del cual «con motivo o en ocasión del ejercicio de sus funciones el servidor público no debe adoptar represalia de ningún tipo o ejercer coacción alguna contra otros servidores públicos u otras personas». Asimismo, habrá que tomar en cuenta lo estipulado en el artículo 39 de la Constitución: «Todos los funcionarios y trabajadores públicos están al servicio de la Nación». Este servicio debe ser prestado libre de cualquier presión, coacción o actos hostiles en contra de los administrados, buscando el respeto y garantía de sus derechos fundamentales.

\section{LAS CONDUCTAS}

En este punto, abordaremos las conductas típicas en el delito de concusión previsto en el Código Penal peruano.

\subsection{El delito de concusión como delito de en- cuentro}

Los delitos de encuentro forman parte de la clasificación general denominada «delitos de participación necesaria», los cuales exigen la intervención de más de un sujeto para la configuración del tipo penal. En particular, los delitos de encuentro tienen una característica especial, y es que en ellos «actúan [...] varias personas hacia una finalidad común, [...] desde direcciones diferentes y de manera complementaria» (Abanto, 2003, p. 68). Dichas conductas "se impelen recíprocamente entre sí, de suerte que el "encuentro" de las distintas actuaciones volitivas produce el efecto de constituir el tipo" (Maurach, 1962, pp. 351-352).

Aquí pueden distinguirse dos tipos de delitos de encuentro: i) aquellos en donde el interviniente necesario es víctima del delito o ii) cuando el interviniente es beneficiado por la conducta del au- tor. En el primer caso, se reconoce la impunidad del interviniente necesario ya que el tipo penal se encuentra dirigido a protegerlo: «en los delitos de encuentro queda fuera del círculo de los posibles autores el partícipe necesario en cuyo beneficio se establece el tipo penal; en los demás casos, la impunidad o punición de partícipe necesario depende, a su juicio, de la interpretación del tipo que se trate» (Jescheck, 1981, p. 979). Como ejemplos, tenemos los delitos de violación sexual (art. 170 CP) y estafa (art. $196 \mathrm{CP}$ ).

En el segundo grupo, encontramos, por ejemplo, los casos de los delitos de cohecho activo y pasivo (arts. 397 y $394 \mathrm{CP}$, respectivamente), tipos penales que sancionan al particular que ofrece ventajas o dádivas a un funcionario público. Así, también, se tiene el delito de nombramiento ilegal (art. $381 \mathrm{CP}$ ), el cual sanciona tanto al funcionario que realiza el nombramiento a una persona que no cuenta con los requisitos correspondientes y al particular que lo acepta. En tales casos específicos se tiene que el legislador ha decidido regular y sancionar las conductas de los intervinientes.

Tomando en cuenta las características del delito de concusión en donde el interviniente necesario es víctima del delito, este nunca podrá ser considerado como cómplice o instigador.

\subsection{Obligar e inducir}

Las conductas que sanciona el Código Penal con el delito de concusión son dos: obligar e inducir. El acto de obligar supone compeler por la fuerza a otro a que haga algo, sin que sea necesaria expresión física sobre el cuerpo de la víctima; tampoco es necesario un amedrentamiento directo, se trata más bien de la amenaza de sufrir algún perjuicio derivado de la administración pública (Abanto, 2003, p. 289) ${ }^{[6]}$.

En palabras de Francisco Carrara, si para obtener el lucro indebido solo se amenaza con el uso de la fuerza privada, ya no habría delito contra la administración pública, sino que estaríamos frente a los delitos de extorsión o hurto violento (En Regalado Rodríguez, 2017, p. 1).

[6] Así, también, lo menciona el R. N. N. ${ }^{\circ}$ 1469-2011 del 16 de octubre de 2012. 
El acto de inducir es aquel por el cual el funcionario persuade, seduce, convence al sujeto de tal manera que inclina su voluntad orientándola a la entrega o promesa de entrega de un bien o beneficio patrimonial (Reátegui, 2014, p. 154). Este acto va desde la persuasión hasta la sugestión, el engaño y el fraude por parte del servidor público para lograr su cometido (Reátegui, 2014, p. 152) ${ }^{[7]}$.

En ambas conductas, media el abuso del cargo por parte del funcionario, pues es este abuso el que incide sobre la voluntad del sujeto al convertirse en un constreñimiento o en una inducción ${ }^{[8]}$.

\subsection{Dar o prometer indebidamente}

Las conductas que realiza el particular frente al funcionario son las de dar o prometer. Para un mejor entendimiento se explicará cada una de ellas.

Dar significa entregar, proporcionar o transferir el beneficio a causa de los actos de obligar o inducir del funcionario (Reátegui, 2014, p. 157). Se trata así de una acción inmediata.

Prometer supone obligarse a efectuar la entrega del beneficio en un futuro próximo. Para que ello suceda la promesa debe ser seria (Reátegui, 2014 , p. 157) y generarse como consecuencia de lo realizado por el agente. Sin embargo, para que sea considerada como una promesa seria no será indispensable que cumpla las formalidades civiles ni que se dé por escrito.

Del mismo modo, el Código menciona que la promesa o entrega del bien debe ser indebida, pues el funcionario obliga o induce respecto de un beneficio que no le corresponde legalmente (Reátegui, 2014, p. 137). Por tanto, no debe tratarse de beneficios económicos que el servidor esté en facultades de recibir.

\section{SITUACIÓN DE LA VÍCTIMA EN EL DELITO DE CONCUSIÓN}

Líneas arriba se mencionó que la persona que entrega o promete un beneficio indebido era víctima de los actos del funcionario. No obstante, es necesario analizar por qué no es imputable teniendo en cuenta que existe el delito de cohecho activo genérico que sí sanciona al particular que da o promete a un funcionario algún tipo de beneficio:

\section{Artículo 397. Cohecho activo genérico}

El que, bajo cualquier modalidad, ofrece, da o promete a un funcionario o servidor público donativo, promesa, ventaja o beneficio para que realice u omita actos en violación de sus obligaciones será reprimido con pena privativa de libertad no menor de cuatro ni mayor de seis años; inhabilitación, según corresponda, conforme a los incisos 1, 2 y 8 del artículo 36; $\mathrm{y}$, con trescientos sesenta y cinco a setecientos treinta días-multa.

El que, bajo cualquier modalidad, ofrece, da o promete donativo, ventaja o beneficio para que el funcionario o servidor público realice u omita actos propios del cargo o empleo, sin faltar a su obligación será reprimido con pena privativa de libertad no menor de tres ni mayor de cinco años; inhabilitación, según corresponda, conforme a los incisos 1, 2 y 8 del artículo 36; y, con trescientos sesenta y cinco a setecientos treinta días-multa.

Si bien en el delito de concusión no se menciona que la entrega o promesa al funcionario se haga para que este cumpla o no con sus obligaciones, es posible deducir que cuando el artículo 382 hace mención al abuso del cargo por parte del funcionario, se hace alusión a las facultades que este transgrede, teniendo en cuenta que se trata de una calidad funcional y no formal del servidor público. Por lo que lo que finalmente interviene con sus obligaciones.

Entonces, el funcionario obliga o induce a la persona a entregar un beneficio para que finalmente ejecute o no sus deberes. Por tanto, es posible señalar preliminarmente que lo efectuado por la víctima (entrega o promesa de un bien o beneficio patrimonial) podría calzar en la conducta

[7] Del mismo modo, lo señala el R. N. N. ${ }^{\circ} 1469-2011$ del 16 de octubre de 2012 y el R. N. N. ${ }^{\circ} 1601-2006$ del 28 de enero de 2009.

[8] Como se menciona en el R. N. 1601-2006 del 28 de enero de 2009. 
descrita por el delito de cohecho activo genérico. Veremos luego que el delito de concusión tiene sus propias particularidades.

\subsection{Causas de justificación}

Siguiendo con el análisis, examinaremos si existe alguna causa de justificación que convierta el comportamiento de la víctima en lícito y conforme a Derecho. Los presupuestos de la causa de justificación son la existencia de una situación de amenaza a bienes jurídicos, la cual hace que la respuesta lesiva del autor sea justificada (Villavicencio, 2017, p. 116). Tenemos así la legítima defensa, el estado de necesidad y el ejercicio legítimo de un derecho.

Conforme al artículo 20, inciso 3, del Código Penal, para que se configure un supuesto de legítima defensa es necesario que exista: i) agresión ilegítima, ii) racionalidad en el medio empleado para defenderse y iii) falta de provocación suficiente de quien se defiende. Es claro que el actuar del sujeto no calza en este supuesto, pues no hay una agresión ilegítima por parte del funcionario.

El estado de necesidad, de acuerdo con el artículo 20, inciso 4, del Código Penal, aplica cuando existe un peligro actual e insuperable que pone en conflicto bienes jurídicos, situación en la que finalmente se protege el bien jurídico de mayor valor. Nuevamente, no se advierte que nos encontremos frente a este supuesto, pues no existen dos bienes jurídicos enfrentados ante un mismo peligro.

Finalmente, el sujeto tampoco está actuando en el ejercicio legítimo de un deber o un derecho. Por lo que no existe causa de justificación que legitime su actuar.

\subsection{Causales de inimputabilidad}

Pasaremos a analizar, entonces, si existe alguna causal de inimputabilidad, pues, como menciona Villavicencio (2017), para imputar responsabilidad penal a una persona será necesario que esta goce de condiciones mínimas que le permitan entender la antijuridicidad de su acción y pueda adecuar su conducta a tal comprensión. Dichas causales son las siguientes: i) la minoría de edad, ii) la grave alteración de la conciencia o de la percepción y iii) la anomalía psíquica. (p. 125)
Como puede apreciarse, lo señalado anteriormente no serían características que calcen en la persona que entrega o promete el bien indebido.

\subsection{Inexigibilidad de actuar conforme a Derecho}

Existen supuestos en los que no se le exige a una persona actuar conforme a Derecho. Tales casos son los siguientes: i) el estado de necesidad exculpante, ii) la obediencia jerárquica y iii) el miedo insuperable. El primero se refiere al conflicto de bienes jurídicos de equivalente valor y el salvaguardo de uno de ellos; el segundo, a la actuación por orden obligatoria de una autoridad competente, en el ejercicio de sus funciones (Villavicencio, 2017, pp. 130-131).

Cabe advertir que tampoco estamos frente a ninguno de los dos primeros supuestos. Por tanto, procederemos a analizar el último de ellos.

\subsubsection{Miedo insuperable de la víctima}

De acuerdo con Mir Puig (2011), el miedo insuperable no debe entenderse como terror, sino como un temor insuperable, de tal manera que la presión motivadora del acto antijurídico no pueda superarse (p. 208). En palabras de Villavicencio (2006), esto implica que la consecuencia - de no actuar conforme al miedo- sería superior a cualquier exigencia media de soportar males y peligros (pp. 642-643).

En el caso tratado a lo largo del artículo, lo que sucede es que existe un temor que resulta del poder del funcionario (Abanto, 2003, pp. 289-290) y de lo que podría hacer en contra del sujeto en caso de no cumplir con lo pedido. Consideramos que, en este caso, no se le puede exigir a la persona actuar conforme a Derecho por encontrarse bajo un supuesto de miedo insuperable. Ello implica que se anula la capacidad de actuar de modo distinto a causa del estado psicológico en el que se encuentra la persona.

\subsection{Error de prohibición}

Como señala Mir Puig (2011), para poder sancionar penalmente a quien comete un delito es necesario que conozca de forma previa que su actuación se hallaba prohibida (p. 552). De lo contrario, estaríamos ante un error de prohibición. 
Entonces, continuando con el análisis de la víctima en el delito de concusión, también podría suceder que el particular sea inducido a error a causa de un engaño efectuado por el funcionario. Con lo cual, la persona creería estar actuando conforme a Derecho al prometer o hacer la entrega del beneficio patrimonial. Por tanto, en tales situaciones estaríamos ante un supuesto de error de prohibición, al existir falta de conocimiento de que el hecho cometido es ilícito.

Es por ello que, en este caso, el particular tampoco respondería penalmente, siempre que se trate de un error invencible. Lo cual significa que no hubo posibilidad de que el error pueda ser superado por el sujeto.

\section{LA INSTRUMENTALIZACIÓN DE LA VÍCTI- MA EN EL DELITO DE CONCUSIÓN}

A partir de lo señalado anteriormente, tenemos que la víctima en el delito de concusión podría encontrarse en una situación de miedo insuperable provocada por la conducta del sujeto activo que la obliga a entregarle un beneficio. Por otro lado, cuando se le induce a engaño, la víctima actuará en error, contexto que será aprovechado por el funcionario público. Así, en ambos casos se aprecia que la víctima es instrumentalizada a través del error o la coacción para obtener el beneficio patrimonial. Si se acompaña lo dicho hasta aquí, podríamos afirmar que, a fin de cuentas, el contexto en el que actúa la víctima va a implicar un supuesto de autoría mediata.

Autor de un delito es «el que tiene dominio del hecho, es decir, aquel sujeto que tiene un poder de conducción de todos los acontecimientos de forma tal que le es posible encauzarlo hacia el objetivo determinado» (Villavicencio, 2014, p. 469). Según el artículo 23 del Código Penal peruano vinculado al tema de la autoría: el que realiza por sí o por medio de otro el hecho punible y los que lo cometan conjuntamente serán reprimidos con la pena establecida para esta infracción. De esta manera, dicho precepto nos permite distinguir tres tipos de autor: i) autor inmediato, ii) autor mediato y iii) coautoría. Existirá autor inmediato si el delito se lleva a cabo por sí mismo (dominio de la acción); será mediato si se comete el delito a través de otra persona por fuerza o engaño (dominio de la voluntad), o habrá coautoría si se realiza con otros a través de la división de trabajo (dominio funcional) (Roxin, 2014, p. 75). Para este caso en específico, profundizaremos en el tema de la autoría mediata.

Conforme a Mir Puig (2011), «Es autor mediato quien realiza el hecho utilizando a otro como instrumento» (p. 388). Esta se produce cuando «el realizador material actúe sin libertad o sin conocimiento de la situación y ello se haya provocado o se aproveche por la persona de atrás, coaccionando o engañando al instrumento, o utilizándole contando con su falta de libertad o su ignorancia de la situación» (Mir Puig, 2011, p. 388). Como decíamos anteriormente, en los casos de concusión, la víctima entrega el beneficio debido al engaño o coacción provocados por el sujeto activo. En el primer caso, si estamos ante un supuesto de error, «la autoría mediata se presenta cuando el hombre de atrás coloca intencionalmente en un error de tipo al intermediario, o se aprovecha de un error ya existente» (Villavicencio, 2014, p. 474). Por otra parte, de tratarse de un supuesto de coacción, «deberá comprobarse el grado de coacción y la influencia de esta sobre la responsabilidad jurídico-penal del intermediario» (Villavicencio, 2014, p. 477). Si lo anterior no se presentara, la «víctima» estaría cometiendo el delito de cohecho activo.

\section{EN RELACIÓN A LA NATURALEZA DEL BIEN O BENEFICIO PATRIMONIAL}

Por otro lado, el delito de concusión menciona que el particular entregará indebidamente un bien o un beneficio patrimonial. Tomando en cuenta lo anterior, se tiene que el bien debe tener un valor patrimonial, por lo que puede tratarse de «dinero, título valor, o cualquier otro provecho, beneficio o goce de contenido económico e, incluso, derechos sobre las cosas» (Abanto, 2003, p. 292). Cuando el tipo penal se refiere a un «bien» nos referiremos a «una cosa cierta, tangible, concreta y con valor patrimonial» (Salinas, 2011, p. 227) que puede ser «convertible en dinero y susceptible de apropiación» (Rojas, 2007, p. 370), comprendiendo bienes muebles, inmuebles o derechos sobre las cosas. Por su parte, el beneficio patrimonial comprende utilidades, créditos, ganancias, acciones, participaciones en empresas (Salinas, 2011, p. 227). 
De esta manera, y siguiendo a James Reátegui, podría diferenciarse entre «bien» y «beneficio patrimonial», de tal manera que el primero se referirá a bienes muebles o inmuebles; mientras que el beneficio patrimonial estaría constituido por regalos, créditos, promociones. Lo importante será que «generen beneficio patrimonial sin desembolso económico» (Reátegui, 2014, p. 159).

Queda claro que el bien o beneficio patrimonial entregado es de la persona sobre la que recae la coacción o inducción ${ }^{[9]}$. En ambos casos, el funcionario público se ve favorecido económicamente a partir del abuso de sus funciones ${ }^{[10]}$.

\section{DESTINATARIO DEL BENEFICIO: EL PRO- VECHO PROPIO O DE TERCERO}

De igual manera, el delito de concusión señala que el bien o beneficio patrimonial será entregado o prometido al funcionario público que obliga o induce, o a un tercero («para sí o para otro»). En otras palabras, el bien o beneficio tendrá como destinatario al funcionario público o a otra persona natural o jurídica (Abanto, 2003, p. 293). En el caso de que se tratara de una persona jurídica, esta no podría ser la propia administración pública.

Por otra parte, si el destinatario es una persona distinta al funcionario público, esta no tendrá la calidad de autor o coautor del delito. Según Fidel Rojas (2007), su conducta podría calificarse como «i) instigador (en la medida que haya generado la decisión en el funcionario); ii) cómplice primario o secundario (si su contribución hizo posible el delito o colaboró en la ejecución del mismo); o iii) receptador (en tanto su conducta se vincule con lo previsto por el artículo 194 del Código Penal» (p. 371).

\section{LA CONSUMACIÓN EN EL DELITO DE CON- CUSIÓN}

La consumación de un delito «consiste en la realización de todos los elementos comprendidos en la figura del delito, que se plasma en la coincidencia total entre los hechos y el tipo delictivo. En lo material, por lo tanto, supone la efectiva lesión del bien jurídico o su puesta en peligro, según sea la clase de infracción» (Quintero, 2005, p. 591). De esta manera, el delito de concusión se consuma, ya sea con la entrega del beneficio indebido o al producirse la promesa por parte del particular que se ve obligado o inducido a ello por el funcionario o servidor público.

Así, pues, se identifica un delito de resultado y de mera actividad para cada modalidad ${ }^{[11]}$, respectivamente (Rojas, 2007, p. 372). Siguiendo a Mir Puig (2011), en los delitos de mera actividad y resultado «importa si el tipo requiere o no que la acción vaya seguida de la causación de un resultado separable espacio-temporalmente de la conducta. En los delitos de mera actividad no es necesario [...] lo contrario sucede en los delitos de resultado" (p. 231). Mir Puig (2011) señala, además, que la diferencia resulta importante a efectos de establecer: «1) la exigencia o no de relación de causalidad entre conducta y resultado; 2) la determinación del tiempo y lugar del delito (solo problemática en los delitos de resultado)» (p. 232).

Por otro lado, el tipo penal no exige que el funcionario cumpla o realice conducta alguna dirigida a cumplir con aquello que hubiera podido comprometerse con la víctima a cambio de la entrega o promesa del bien o beneficio patrimonial.

\section{DIFERENCIAS Y SIMILITUDES CON OTROS DELITOS}

Luego del análisis realizado al delito de concusión, podemos advertir que tendría ciertas similitudes con otros tipos penales. En particular, con delitos como los de cohecho (pasivo), coacción y extorsión. Así, resulta importante establecer cuáles serían las principales semejanzas y diferencias con estos tipos penales.

[9] Según la Sala Penal Transitoria RN 3183-2015 del 8 de agosto de 2016.

[10] Según la Penal Permanente RN 3128-2015 del 31 de mayo de 2016.

[11] Así, también, el Recurso de Nulidad N. ${ }^{\circ}$ 3188-2011 emitido por la Sala Penal Permanente de la Corte Suprema de Justicia de la República el 30 de enero de 2013. 


\subsection{El delito de concusión y el delito de cohecho (pasivo)}

El delito de cohecho pasivo se encuentra previsto en los artículos 393 y 394 del Código Penal peruano:

\section{Artículo 393. Cohecho pasivo propio}

El funcionario o servidor público que acepte o reciba donativo, promesa o cualquier otra ventaja o beneficio, para realizar u omitir un acto en violación de sus obligaciones o el que las acepta a consecuencia de haber faltado a ellas, será reprimido con pena privativa de libertad no menor de cinco ni mayor de ocho años e inhabilitación conforme a los incisos 1 y 2 del artículo 36 del Código Penal y con ciento ochenta a trescientos sesenta y cinco días-multa.

El funcionario o servidor público que solicita, directa o indirectamente, donativo, promesa o cualquier otra ventaja o beneficio, para realizar $u$ omitir un acto en violación de sus obligaciones o a consecuencia de haber faltado a ellas, será reprimido con pena privativa de libertad no menor de seis ni mayor de ocho años e inhabilitación conforme a los incisos 1 y 2 del artículo 36 del Código Penal y con trescientos sesenta y cinco a setecientos treinta días-multa.

El funcionario o servidor público que condiciona su conducta funcional derivada del cargo o empleo a la entrega o promesa de donativo o ventaja será reprimido con pena privativa de libertad no menor de ocho ni mayor de diez años e inhabilitación conforme a los incisos 1 y 2 del artículo 36 del Código Penal y con trescientos sesenta y cinco a setecientos treinta días-multa.

\section{Artículo 394. Cohecho pasivo impropio}

El funcionario o servidor público que acepte o reciba donativo, promesa o cualquier otra ventaja o beneficio indebido para realizar un acto propio de su cargo o empleo, sin faltar a su obligación, o como consecuencia del ya realizado, será reprimido con pena privativa de libertad no menor de cuatro ni mayor de seis años e inhabilitación conforme a los incisos 1 y 2 del artículo 36 del Código Penal y con ciento ochenta a trescientos sesenta y cinco días-multa.
El funcionario o servidor público que solicita, directa o indirectamente, donativo, promesa o cualquier otra ventaja indebida para realizar un acto propio de su cargo o empleo, sin faltar a su obligación, o como consecuencia del ya realizado, será reprimido con pena privativa de libertad no menor de cinco ni mayor de ocho años e inhabilitación conforme a los incisos 1 y 2 del artículo 36 del Código Penal y con trescientos sesenta y cinco a setecientos treinta días-multa.

De la comparación entre los delitos de cohecho y concusión, podemos identificar los siguientes puntos en común. En primer lugar, que en ambos delitos el sujeto activo es un funcionario que abusa del ejercicio del poder público, de su posición o calidad especial. En segundo lugar, la recepción del beneficio o promesa, en donde el funcionario público obtiene un beneficio personal.

En cuanto a las diferencias, observamos que en el delito de concusión el beneficio se obtiene a través de la obligación (violencia, amenaza) o del engaño, supuestos que vician la voluntad del particular. Con lo cual, el particular que entrega o promete el beneficio y sobre el que recae la violencia, amenaza o engaño no responderá penalmente al ser considerado víctima de este delito. En contraposición, en los delitos de cohecho (pasivos) existe libertad contractual entre el funcionario o servidor público y el particular, de tal manera que en tal supuesto no existen medios que vicien o distorsionen la voluntad (Montoya, 2015, p. 105).

En estos casos, por el contrario, el particular que entrega o promete podrá responder penalmente a título de autor del delito de cohecho activo genérico.

Así, también, Fidel Rojas (2007) señala como diferencia el hecho de que en el caso del delito de concusión resulta irrelevante que la entrega o promesa de bien o beneficio patrimonial se realice con el propósito de que el funcionario público cumpla u omita un acto vinculado con sus funciones (p. 375).

\subsection{El delito de concusión y el delito de coacción}

De otro lado, el delito de coacción se encuentra previsto en el artículo 151 del Código penal. El mismo que sanciona: 


\section{Artículo 151. Coacción}

El que, mediante amenaza o violencia, obliga a otro a hacer lo que la ley no manda o le impide hacer lo que ella no prohíbe será reprimido con pena privativa de libertad no mayor de dos años.

En términos generales, este delito busca proteger la libertad de las personas, por lo que «criminaliza y reprime conductas que pretenden desconocer, coactar o condicionar ilícita o arbitrariamente su ejercicio» (Prado, 2017, p. 67). La principal semejanza que existe entre el delito de concusión y el de coacción es que en ambos casos el autor obliga a una persona a realizar una conducta que la ley no manda. De igual manera, en ambos casos la persona obligada es víctima del delito.

Por otra parte, entre las diferencias más claras destacan el hecho de que en el delito de concusión el autor es un funcionario o servidor público, mientras que en el delito de coacción podría tratarse de un funcionario público o de un particular. Así, también, tenemos que, en el delito de concusión, las conductas típicas no se limitan a obligar a una persona a entregar o prometer un bien o beneficio patrimonial indebido. Y ello en tanto que también se configura el delito a través de la inducción o engaño, tal y como hemos visto en líneas precedentes. Además, en el delito de concusión se requiere que la víctima actúe de determinada manera (entregando o prometiendo), mientras que en el delito de coacción la conducta de la víctima deberá enmarcarse, aunque de manera general, en lo que pueda identificarse como «hacer lo que la ley no manda" o «lo que ella no prohíbe». Es decir, en el delito de coacción la actuación de la víctima puede comprender actuaciones distintas a las de la entrega o promesa de un bien o beneficio patrimonial.

\subsection{El delito de concusión y el delito de extorsión}

Finalmente, se pueden apreciar ciertas similitudes y diferencias entre los delitos de concusión y de extorsión. El delito de extorsión se encuentra previsto en el artículo 200 del Código Penal, según el cual:

\section{Artículo 200. Extorsión}

El que mediante violencia o amenaza obliga a una persona o a una institución pública o pri- vada a otorgar al agente o a un tercero una ventaja económica indebida u otra ventaja de cualquier otra índole será reprimido con pena privativa de libertad no menor de diez ni mayor de quince años. [...]

Entre las semejanzas podemos advertir que en ambos delitos la persona que se ve obligada a entregar una ventaja económica indebida será víctima del delito.

Entre las diferencias destacan el hecho de que en el delito de concusión el autor es un funcionario público, mientras que en el de extorsión podría ser sujeto activo un funcionario o un particular. En este punto, Fidel Rojas (2007) señala que en la concusión «se hace valer la calidad e importancia del cargo para extorsionar» (pp. 374-375). Además, se tiene que, en el caso de la concusión, se obliga $o$ induce a entregar o prometer un beneficio a una persona natural o jurídica, siendo en este último caso distinta a la administración pública. Como puede apreciarse, en el caso del delito de extorsión, sí está previsto el caso en el que se le exija una ventaja económica a una institución pública. Asimismo, se tiene que, entre otras conductas, la extorsión sanciona la toma de locales, la obstaculización de vías de comunicación, impedir el libre tránsito de la ciudadanía, el normal funcionamiento de los servicios públicos o la ejecución de obras legalmente autorizadas.

\section{LA PENA EN EL DELITO DE CONCUSIÓN}

El delito de concusión prevé tres tipos de pena. En primer lugar, la pena privativa de la libertad que será no menor de dos ni mayor de ocho años. En segundo lugar, se aplicará la pena de inhabilitación, según corresponda, conforme a los incisos 1, 2 y 8 del artículo 36 del Código Penal. De esta manera, por ejemplo, conforme al inciso 1, la pena de inhabilitación implicará: «Privación de la función, cargo o comisión que ejercía el condenado, aunque provenga de elección popular». El inciso 2, a su vez, se refiere a la «Incapacidad o impedimento para obtener mandato, cargo, empleo o comisión de carácter público», mientras que el inciso 8, a la «Privación de grados militares o policiales, títulos honoríficos $u$ otras distinciones que correspondan al cargo, profesión u oficio del que se hubiese servido el agente 
para cometer el delito, respectivamente». En tercer lugar, el delito de concusión se va a sancionar con una pena de ciento ochenta a trescientos sesenta y cinco días-multa.

\section{A MODO DE CONCLUSIÓN}

El presente texto ha tratado de revisar los aspectos más importantes del delito de concusión en el Código Penal peruano. Tal y como puede apreciarse, se trata de un delito con ciertas particularidades y elementos que deberían motivar a la investigación por parte de estudiantes y académicos.

Los principales aspectos a tener en cuenta son los siguientes:

i) se trata de un delito de encuentro, en el cual actúan el funcionario o servidor público con un tercero, donde este último es víctima del agente estatal. Si bien el sujeto activo de este delito será el funcionario, el sujeto pasivo siempre será el Estado y no la víctima;

ii) el particular hace entrega o promete un beneficio debido a que se encuentra en un contexto de miedo insuperable o error de prohibición, motivos por los cuales su actuar no es sancionado;

iii) en caso se compruebe que el particular no actuó bajo miedo insuperable o error de prohibición, este respondería por el delito de cohecho activo;

iv) este delito podría concurrir con los tipos penales del delito de cohecho pasivo, coacción y extorsión, para lo cual es importante tener claras las diferencias objetivas y subjetivas entre los mismos.

De esta forma esperamos contribuir a que se fomente la discusión y reflexión en torno al delito de concusión.

\section{REFERENCIAS BIBLIOGRÁFICAS}

Abanto, M. (2003). Los delitos contra la administración pública en el Código penal peruano. Lima: Palestra.

Jescheck, H. H. (1981). Tratado de Derecho Penal. Parte General. Traducción y adiciones de De- recho español por MIR PUIG, Santiago y Francisco MUÑOZ CONDE. Barcelona: Bosch.

Maurach, R. (1962). Tratado de Derecho Penal. Tomo II. Traducido por Córdoba Roda, Juan. Barcelona: Ariel.

Meini, I. (2012). Temas de Autoría y participación en delitos contra la Administración Pública. Boletín Proyecto Anticorrupción, (13). Lima: Idehpucp. Recuperado de: https://bit.ly/2oXYuoG (Consultado el 19 de octubre de 2019).

Mir Puig, S. (2011). Derecho Penal Parte General. 10. ${ }^{a}$ ed. Barcelona: Reppertor.

Procuraduría Pública Especializada en Delitos Anticorrupción. (diciembre de 2018). Información Estadística PPEDC. Lima. Recuperado de: https://bit.ly/2VePvcL (Consultado el 8 de abril de 2019).

Quintero, G. (2005). Parte General del Derecho Penal. Navarra: Editorial Aranzadi.

Ramos Mejía, E. (1963). El delito de concusión. Buenos Aires: Ediciones Depalma.

Reátegui, J. (2014). Delitos cometidos por funcionarios en contra de la Administración Pública. Lima: Jurista Editores.

Regalado, J. (2017). Informe de Suficiencia Profesional de Expediente: Expediente Penal 054-2012 Delitos de Concusión (Trabajo de Suficiencia Profesional para obtener el Título de Abogado). Universidad San Pedro, Chimbote.

Roxin, C. (2014). Derecho Penal. Parte General. Tomo II. Especiales formas de aparición del delito. Navarra: Editorial Aranzadi.

Rojas, F. (2007). Delitos contra la Administración Pública. 4. ${ }^{a}$ ed. Lima: Grijley.

Sala Penal Permanente de La Corte Suprema de Justicia de La República. (30 de enero de 2013). Recurso de Nulidad N. ${ }^{\circ}$ 3188-2011.

Sala Penal Permanente de La Corte Suprema de Justicia de La República. (31 de mayo de 2016). Recurso de Nulidad N. ${ }^{\circ} 3128-2015$.

Sala Penal Transitoria de La Corte Suprema de Justicia de La República. (8 de agosto de 2016). Recurso de Nulidad N. ${ }^{\circ}$ 3183-2015. 
Salinas, R. (2011). Delitos contra la Administración Pública. 2. ${ }^{a}$ ed. Lima: Grijley.

Villavicencio, F. (2006). Derecho Penal Parte General. Lima: Grijley.
(2014). Derecho penal: parte general. Lima: Grijley.

(2017). Derecho Penal Parte General. Lima: Fondo Editorial PUCP. 